\title{
PATHOLOGICAL SUB TROCHANTERIC FRACTURE OF FEMUR FOLLOWING PELVIC IRRADIATION FOR CA CERVIX: A CASE REPORT
}

Shiva Naik R11, Venkateshulu E2 ${ }^{2}$ Roopesh Kumar A. C 3

\section{HOW TO CITE THIS ARTICLE:}

Shiva Naik R, Venkateshulu E, Roopesh Kumar A. C. "Pathological Sub Trochanteric Fracture of Femur following Pelvic Irradiation for CA Cervix: A Case Report". Journal of Evolution of Medical and Dental Sciences 2014; Vol. 3, Issue 73, December 25; Page: 15453-15456, D0I: 10.14260/jemds/2014/4083

ABSTRACT: INTRODUCTION: Subtrochanteric fractures account for approximately 10-30\% of all hip fractures, and they affect persons of all ages. Most frequently, these fractures are seen in 2 patient populations, namely older osteopenic patients after a low-energy fall and younger patients involved in high-energy trauma. A newer population of patients experience subtrochanteric fractures after bisphosphonate use. CASE PRESENTATION: A 45year old Indian woman presented at our orthopaedic outpatients department with 4 months history of pain in left hip and a 1 month history of inability to walk. She had pelvic irradiation for carcinoma of cervix 1 year earlier. Pelvic radiograph confirmed sub trochanteric fracture of left femur. CONCLUSION: Patients with hip pain who have been treated with pelvic irradiation should be thoroughly investigated for hip fractures.

KEYWORDS: Sub trochanter, CA cervix.

INTRODUCTION: Subtrochanteric fractures account for approximately 10-30\% of all hip fractures, and they affect persons of all ages. Most frequently, these fractures are seen in 2 patient populations, namely older osteopenic patients after a low-energy fall[1,2] and younger patients involved in highenergy trauma. A newer population of patients experience subtrochanteric fractures after bisphosphonate use. These so-called atypical fractures have a transverse or short oblique pattern with cortical thickening and medial cortical "beak."

In elderly patients, minor slips or falls that lead to direct lateral hip trauma are the most frequent mechanism of injury.[2,3] This age group is also susceptible to metastatic disease that can lead to pathologic fractures. In younger patients, the mechanism of injury is almost always high-energy trauma, either from direct lateral trauma (eg, motor vehicle accident [MVA]) or from axial loading (eg, a fall from height). Gunshot wounds cause approximately $10 \%$ of high-energy subtrochanteric femur fractures. Iatrogenic fractures may also occur secondary to stress risers following previous surgery on the proximal femur. ${ }^{[4]}$

However it is well documented that therapeutic radiation can result in bone damage and may increase the risk of fracture. ${ }^{[5]}$ Magnetic resonance imaging and standard radiographs of the hips are useful diagnostic tools.[6] We report a case of sub trochanteric femoral fracture presenting after radiotherapy for a gynaecological malignancy.

CASE PRESENTATION: A 45 year old woman came to our orthopaedics outpatients department in November 2014 with a 4 months history of pain in left hip and a 1 month history of inability to walk. The pain was insidious and was associated with a worsening limp, which required her to walk with the aid of a walking stick. She had been bedridden for about 1 month before presentation but she had no history of falls. 
She had been diagnosed with a stage 3b squamous cell carcinoma of the cervix 1 and half years before presentation and was treated primarily with 100 Gy of external radiation therapy for 50 days in fractioned doses and had been symptom free thereafter. A pelvic radiograph showed sub trochanteric fracture of left femur (Figure 1). She underwent closed reduction and internal fixation with proximal femoral nail and bone grafting (Figure 2).

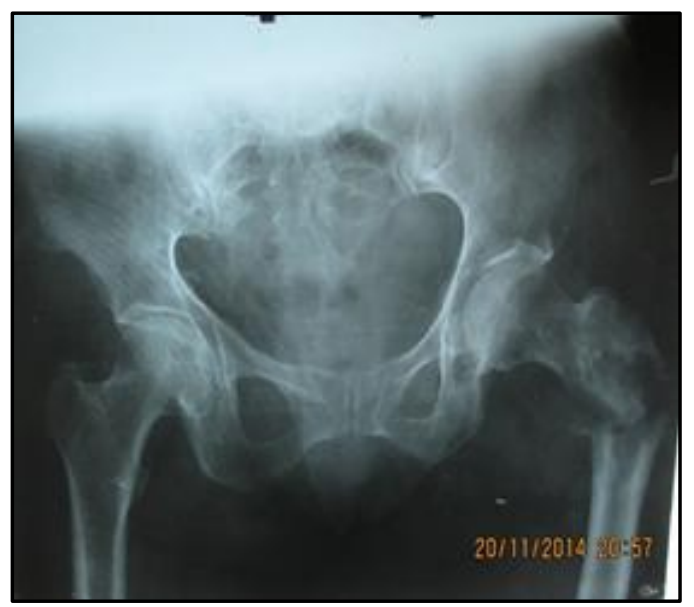

Fig. 1

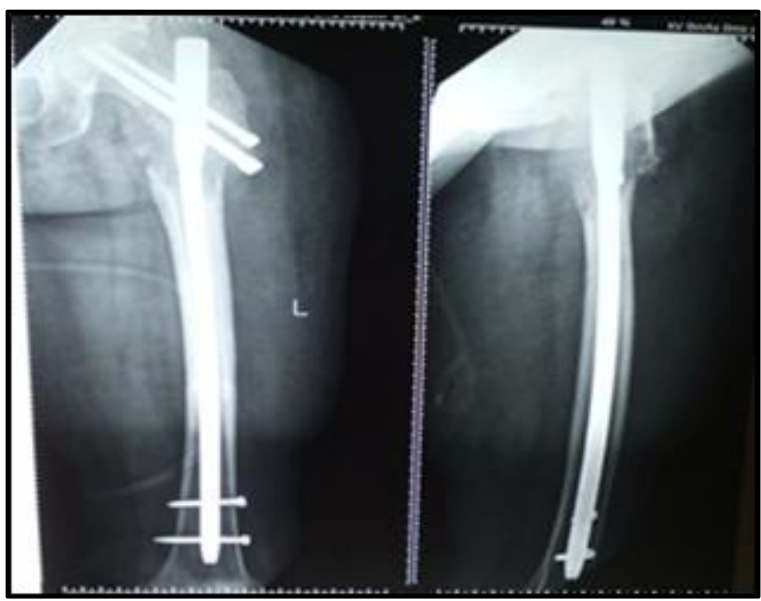

Fig. 2

DISCUSSION: Radiotherapy is the mainstay of treatment of advanced female pelvic malignancies, either in curative or palliative settings.[7] The bony structures of the pelvis and groin lie in close proximity to the genitourinary pelvic organs, gastrointestinal pelvic organs, and the lymphatic drainage of these organs. Therefore, during irradiation, there is an associated high rate of morbidity related to pelvic organs. However, damage to the bones is rarely taken into account, because they are relatively radio resistant. The main evidence of the effect of irradiation on fracture risk comes from a long term follow-up study of two European randomized trials (Stockholm 1 and 2) evaluating the effect of short course irradiation in patients with operable rectal cancer. ${ }^{[8,9]}$ It was established that the patients who underwent short course irradiation were twice as likely to be admitted to hospital with hip fractures as patients who did not undergo irradiation.

A search through the medical records in our hospitals and in our regional journals showed no patient presenting with hip fracture following pelvic irradiation. This may indicate that Indians are less likely to develop pelvic fractures following irradiation, although Nancy et al[5] did not find any statistical interaction between race and irradiation therapy. The patient presented with hip pain, for which she was treated with analgesics only; no radiological investigation was done until the patient was bed ridden.

The presentation of this patient fits into the classical symptom and signs suggested by Lavelle, "prodromal pain localised to the hip or radiating to the knee, as might occur with a slipped femoral epiphysis. Although the patient is able to walk, coxavara deformity may have already occurred".[10] Hip pain in patients treated with pelvic irradiation should make the physician suspect radiation induced insufficiency fractures of the pelvis. In the study by Feltl et al.[7] all patients with symptomatic pelvic bone fractures had pain as the first symptom. 
CONCLUSION: Indians are predisposed to hip fractures following pelvic irradiation. Hip pain in patients who have had pelvic irradiation should therefore be thoroughly investigated for hip fractures. It should also be noted that complications following irradiation may present months or years later.

CONSENT: Written informed consent was obtained from the patient for publication of this case report and any accompanying images. A copy of the written consent is available for review by the Editor-in-chief of this journal.

\section{REFERENCES:}

1. Nieves JW, Bilezikian JP, Lane JM, Einhorn TA, Wang Y, Steinbuch M, et al. Fragility fractures of the hip and femur: incidence and patient characteristics. Osteoporos Int. May 30 2009; [Medline].

2. Ekström W, Németh G, Samnegård E, Dalen N, Tidermark J. Quality of life after a subtrochanteric fracture: a prospective cohort study on 87 elderly patients. Injury. Apr 2009; 40 (4): 371-6. [Medline].

3. Boyd AD, Wilber JH. Patterns and complications of femur fractures below the hip in patients over 65 years of age. J Orthop Trauma. 1992; 6 (2): 167-74. [Medline].

4. Kloen P, Rubel IF, Lyden JP, Helfet DL. Subtrochanteric fracture after cannulated screw fixation of femoral neck fractures: A report of four cases. J Orthop Trauma. 2003; 17: 225233. [Medline].

5. Nancy NB, Elizabeth BH, Joel ET, Sara BD, Beth AV: Risk of pelvic fractures in older women following pelvic irradiation. JAMA 2005, 23/30:2587-2593.

6. Zuckerman JD, Shin SS, Polatsch DB, Schweitzer M: Concurrent bilateral femoral neck stress fractures and osteonecrosis of the hip. J Bone Joint Surg 2006, 88:857-860.

7. Feltl D, Vosmik M, Jirasek M, Stahalova V, Kubes J: Symptomatic osteoradionecrosis of the pelvic bones in patients with gynaecological malignancies - result of long term follow up. Int J Gynecol Cancer 2006, 16:478-483.

8. Cedermark B, Johansson H, Rutqvist LE, Wilking N: Stockholm 1 trial of preoperative short term radiotherapy in operable rectal carcinoma: a prospective randomized trial. Cancer 1995, 75:2269-2275.

9. Stockholm Colorectal Cancer Study Group: Randomized study on preoperative radiotherapy in rectal carcinoma. Ann Surg Oncol 1996, 3:423-430.

10. LaVelle DG: Fractures of hip. In Campbell's Operative Orthopaedics volume 3.10 th edition. Edited by: Canale ST. Philadelphia: Mosby: 2003. 


\section{CASE REPORT}

\section{AUTHORS:}

1. Shiva Naik R.

2. Venkateshulu E.

3. Roopesh Kumar A. C.

\section{PARTICULARS OF CONTRIBUTORS:}

1. Associate Professor, Department of Orthopaedics, VIMS, Bellary.

2. Professor, Department of Orthopaedics, VIMS, Bellary.

3. Post Graduate Student, Department of Orthopaedics, VIMS, Bellary.
NAME ADDRESS EMAIL ID OF THE CORRESPONDING AUTHOR:

Dr. Shiva Naik R, Associate Professor,

Department of Orthopaedics, \#B16, VIMS Campus, Cantonment, Bellary-583104.

Email: drshivanaik@rediffmail.com

Date of Submission: 09/12/2014.

Date of Peer Review: 10/12/2014.

Date of Acceptance: 17/12/2014.

Date of Publishing: 24/12/2014. 